\title{
Invited comment to: Open retromuscular large mesh reconstruction of lumbar incisional hernias including the atrophic muscular area. Y. Renard, L. de Mestier, A. Cagniet et al.
}

\author{
R. K. J. Simmermacher ${ }^{1}$
}

Received: 16 March 2017 / Accepted: 22 March 2017/Published online: 31 March 2017

(c) The Author(s) 2017. This article is an open access publication

\section{Introduction}

French surgeons already for years are front-runners in the development and execution of sophisticated solutions for challenging problems in the treatment of abdominal wall pathology. The recently published experience on the treatment of lumbar incisional hernia again is an example of this [1]. It touches several issues concerning this entity that deserve separate and possibly more intense discussion.

\section{Definition of incisional lumbar herniae}

Lumbar incisional herniae must be more common than the numbers given in literature, and although a clear definition should not be too difficult the term itself contains many different phenotypes. First and according to Korenkov's definition a real defect in all three muscles that form the lateral abdominal wall [2]. Second the incomplete or interstitial incisional hernia in which there is no defect in the external aponeurosis but only in the internus/transversus complex which most probably was not properly closed in the original operation in the first place. Thirdly there are traumatic lumbar abdominal defects, often caused by seatbelts or in former times by cancellous bone-harvesting procedures out of the iliac crest by orthopedic surgeons, where the latter forms a real incisional hernia, while in case

This comment refers to the article available at doi:10.1007/s10029016-1570-y.

\footnotetext{
R. K. J. Simmermacher

R.K.J.Simmermacher@umcutrecht.nl

1 UMC Utrecht, Utrecht, The Netherlands
}

of a traumatic abdominal wall rupture, mostly due to a blunt trauma, there will be no scar. These conditions are different to defects because of tissue-loss of the abdominal wall, caused by deliberate removal of muscle-tissue for oncologic reasons.

One should realize that contrary to the midline laparotomy via the linea alba a "lumbotomy" might refer to a "classic" one, a vertical pararectal incision, a dorsal lumbotomy variant or variations on these [3], indicating that, as there does not exist a so-called standard lumbotomy, there will be no standard incisional lumbar herniae and subsequently no real standard technique to repair such a hernia. However, Renard presents a standard principle how to deal with this condition.

\section{Muscular atrophy}

In addition to the differences of the different types of incisional lumbar hernia all of them, too, might be accompanied by atrophy of the muscles either already before the reconstructive operation, however rare in the traumatic abdominal wall rupture, or post-operatively as the repair itself might cause damage to the intercostal nerves. Muscular atrophy in combination with abdominal wall defects is hardly been addressed before, but is an important issue in lumbar herniae. Preoperatively the bulge due to the hernia does not tell us whether it is the hernia itself, pure muscular atrophy or a combination. Computed tomography in lumbar incisional hernia therefore is a crucial prerequisite for proper diagnostics as well as treatment planning, comparing the hernia site with the (hopefully healthy) opposite site. However, it might be difficult to realize what the functional status of the muscle is, whether the endpoint of atrophy has been reached or if 
the muscle-mass still is shrinking. The latter depends on the moment of damage to the intercostal nerve causing the atrophy, but we are often not aware of the natural course of the muscular volume due to its atrophy. If we would know more about it, better planning of a repair should be possible. Unfortunately muscular atrophy also might be the result of our attempt to repair an incisional hernia leaving our patient with the idea that nothing has been done as the bulge returns causing the same mechanical problems as before, although the defect is closed.

\section{Reconstruction of the lateral abdominal wall}

Given the many possible surgical techniques of a lumbotomy, the often apparently impressive loss of domain in many of the incisional hernia, that might develop, mostly can be reduced if the patients turn to the contralateral decubitus position, which is a clear indication that reconstruction without a muscular flap plasty should be possible. Furthermore, this includes that in case a mesh is used the purpose will be augmentation rather than bridging. The technique to be used depends on the anatomy and therefore knowledge of it is paramount [4]. Vest-over-pants closure/ repair of the atrophic muscles seems to regain some muscle volume, but it might be anticipated that shrinking of the muscle will continue, as we cannot assume the status preor perioperatively. In midline herniae vest-over-pants repair is ill-advised because of high number of failure [5]. I do not know what will happen to the two layers of the same muscle that are put on each other. Will there be mutual tissue-ingrowth?

\section{Open or scopic technique}

There is an ongoing discussion on this subject in most abdominal wall defects. There is literature concerning the laparoscopic repair of incisional lumbar herniae, showing that it is feasible to do in small and moderate defects [6] and telling us that more numbers are needed to show the alleged superiority [7,8]. Given the fact that the many different types of lumbar incisions create rather different types of incisional hernia and the fact that in most cases it will not be necessary to create a larger abdominal volume, open repair with careful, sometimes rather extensive, dissection of the different layers, followed by separate closure of these layers would be advisable, irrespective of the use of mesh. For sure, the technique described by Renard [1], using a very large mesh for augmentation will not be applicable in a laparoscopic fashion. However, I am wondering how the surgeons succeed in passing the linea alba to the contralateral side if the pre-peritoneal space includes that above the linea arcuata. Fixation with slow-absorbable sutures for positioning, until tissue-ingrowth takes it over should be standard.

\section{Tension on the mesh}

In the technique described two points seem to be crucial. First the use of a very large mesh, compared to the size of the defect. This idea dates back to Rives and Stoppa, who described this feature already years ago in the repair of inguinal hernia and as one of the co-authors then is the coauthor of Renard now, this is not surprising [9]. The second key-point is the deliberately applied tension on the mesh and is an important issue to remodel part of the abdominal wall. This tension applied to the mesh, as Renard describes it, has to be maintained and this seems to be a novel and a, so far, scarcely described feature. Currently "tension" in combination with a repair of any type of abdominal wall repair seems to be a forbidden word. At least I could not find anything about in the literature of the last 4 years. However one might wonder for what price and whether the mesh will be able to maintain tension. Fixation of the mesh with whatever type of suture transmuscular and to the ribs often results in long-lasting pain until the suture dissolves. It is questionable if the scar-tissue that grows through the mesh will be able to maintain the tension. Furthermore, there is limited knowledge about the fact whether the mesh used, will be able to keep its tension given in the production process. In bridging hernia defects meshes showed to bulge after a certain time although this might also be dependent on the fixation used. Given the experience of vascular surgeons with polyester prostheses it might take some time before they lose the tension [10].

\section{Conclusion}

Again France shows her front-runner's position by describing a large series of the rather infrequent incisional lumbar herniae treated in a fixed, though open, operative way, in which unusual big overlap of the mesh in a pre/retro-peritoneal position with deliberate tension in all directions applied, are the key-elements. The results are impressive and the fact that post-operative chronic pain as outcome measurement is included is an important adjunct. Standardization of the repair of lumbar incisional herniae, however, still is difficult as there are so many types of incisional hernia due to the many different incisions used in the first operation. Renard, however, shows us a direction to start with. Possibly many readers will have experience, often with their own technique(s), although hardly anyone will have large series, which one would love to share and discuss. This, 
again, shows the need to register your cases in a standardized format and easily accessible and free data-base, which provides the possibility to share your data [11]. EuraHS offers such a platform (http://www.eurahs.eu/).

Conflict of interest The author declares that he has no conflicts of interest.

Human and animal rights This article does not contain any studies with human participants or animals performed by the author.

\section{Informed consent None.}

Open Access This article is distributed under the terms of the Creative Commons Attribution-NonCommercial 4.0 International License (http://creativecommons.org/licenses/by-nc/4.0/), which permits any noncommercial use, distribution, and reproduction in any medium, provided you give appropriate credit to the original author(s) and the source, provide a link to the Creative Commons license, and indicate if changes were made.

\section{References}

1. Renard Y, de Mestier L, Cagniet A et al (2017) Open retro muscular large mesh reconstruction of lumbar incisional hernias including the atrophic muscular area. Hernia (epub ahead of print)

2. Korenkov M, Paul A, Sauerland S et al (2001) Classification and treatment of incisional: results of an experts' meeting. Langenbecks Arch Surg 386:65-73

3. Dols LF, Kok FN, Ijzermans JN (2010) Live donor nephrectomy: a review of evidence of surgical techniques. Transplant Int 23:121-130

4. Stumpf M, Conze J, Pescher A et al (2009) The lateral incisional hernia: anatomical considerations for a standardized retromuscular sublay repair. Hernia 13:293-297

5. Lau H, Patil NG (2003) Umbilical hernia in adults. Surg Endosc $17: 16-20$

6. Moreno-Egea A, Baena EG, Calle MC et al (2007) Controversies in the Current management of Lumbar Hernias. Arch Surg 142:82-88

7. Moreno-Egea A, Torralba-Martines JA, Morales G et al (2005) Open vs laparoscopic repair of secondary lumbar hernias. Surg Endosc 19:184-187

8. Ferrarese A, Enrico S, Solej M et al (2016) Laparoscopic management of non-midline incisional hernia: a multicentric study. Int J Surg 33:S108-S113

9. Stoppa R, Rives J, Warlaumont C et al (1984) The use of Dacron in the repair of hernias of the groin. Surg Clinc North Am 62:269-285

10. Wilson SE, Krug R et al (1997) Late disruption of Dacron aortic grafts. Ann Vas Surg 11:383-386

11. Montgomery A (2016) The best of two worlds: a new innovative laparoscopic Rives-Stoppa technique for ventral/incisional hernias-"the Brazilian technique". Hernia 20:267-270 